\title{
Action of $\mathrm{N}$-Succinyl and $\mathrm{N}, \mathrm{O}$-Dicarboxymethyl Chitosan Derivatives on Chlorophyll Photosynthesis and Fluorescence in Drought-Sensitive Maize
}

\author{
Caroline Oliveira dos Reis ${ }^{1}$. Paulo César Magalhães ${ }^{2} \cdot$ Roniel Geraldo Avila $^{3} \cdot$ Lorena Gabriela Almeida $^{3}$. \\ Valquíria Mikaela Rabelo ${ }^{1}$. Diogo Teixeira Carvalho ${ }^{4}$. Daniela Ferreira Cabral ${ }^{5}$. Décio Karam ${ }^{2}$. \\ Thiago Correa de Souza ${ }^{1}$ (D)
}

Received: 1 June 2018 / Accepted: 5 October 2018 / Published online: 31 October 2018

๑) Springer Science+Business Media, LLC, part of Springer Nature 2018

\begin{abstract}
Chitosan induces plant tolerance to various abiotic stresses, including water deficit. However, its use may be limited, due to its constitution and low solubility in water. Thus, chemical modifications were proposed in this study with the objective of potentializing its biological effects in maize plants. The derivatives were semi-synthesized ( $N$-succinyl and $N, O$-dicarboxymethyl) and, together with chitosan, they were applied, via the leaf, in a drought-sensitive maize hybrid (BRS1030) under pre-flowering water deficit. The water deficit was maintained for 15 days and the analyses were performed at the beginning and end of stress, and also in rehydration. Leaf water potential, gas exchange, chlorophyll fluorescence, and content of chloroplastidic pigments were evaluated. The use of the derivatives modulated photosynthesis parameters, affecting the involved mechanisms, such as stomatal activity, water use efficiency and photosystem II activity. Chlorophyll fluorescence indicated that the antenna complex was damaged by the water deficit condition, with a decrease in the energy flux in the electron transport chain and in the photochemical phase of photosynthesis. However, the spraying of chitosan derivatives induced tolerance to water deficit, suggesting that chitosan derivatives are more bioavailable to plants. Water stress decreases pigment content, but both the application of chitosan and derivatives increased these contents. It is concluded that chitosan derivatives improved the photosynthetic parameters in maize susceptible to drought, inducing tolerance to this stress, and the possible reasons and consequences are discussed.
\end{abstract}

Keywords Water deficit · Zea mays L. Gas exchange $\cdot$ Biostimulant $\cdot$ Quenching $\cdot$ Leaf water potential

Thiago Correa de Souza

thiagonepre@ hotmail.com

1 Institute of Natural Sciences-ICN, Federal University of Alfenas - UNIFAL-MG, Gabriel Monteiro Street, 700, P. O. Box 37130-000, Alfenas, MG, Brazil

2 Maize and Sorghum National Research Center, P. O. Box 151, Sete Lagoas, MG 35701-970, Brazil

3 Section of Plant Physiology, Department of Biology, Federal University of Lavras, Campus Universitário, P. O. Box 37, Lavras, MG 37200-000, Brazil

4 Faculty of Pharmaceutical Sciences, Federal University of Alfenas - UNIFAL-MG, Gabriel Monteiro da Silva Street, 700, P.O. Box 37130-000, Alfenas, MG, Brazil

5 Chemistry Institute, Federal University of Alfenas - UNIFAL-MG, Street Gabriel Monteiro da Silva, 700, P.O. Box 37130-000, Alfenas, MG, Brazil

\section{Introduction}

One of the greatest challenges facing the world today in relation to food safety is the pressure on natural resources, especially water availability. Water performs various functions within plants, such as acting as a carrier of solutes and nutrients, as a structural support through turgor pressure and as a reactant in photosynthesis. Its absence has a direct impact on plant production, mainly due to the derangements caused in most of the photosynthetic components, including electron transport in the thylakoids and $\mathrm{CO}_{2}$ fixation by the reduction in stomatal opening and/or the inhibition of Calvin cycle enzymes (Anjum et al. 2011; Souza et al. 2013a). Therefore, the ability of plants to withstand such stress is of utmost importance for agribusiness development in any country, especially in large crops such as maize. 
Irrigated agriculture makes an important contribution to agricultural production, with about $40 \%$ of agricultural food and commodities in $17 \%$ of the cultivated land. Irrigation uses more than $70 \%$ of the water withdrawn from rivers. An increase in the use of irrigation to meet food needs in the coming years will, however, be impracticable due to the decline in water resources and increasing competition for clean water. Water dependency becomes a critical constraint on progress and threatens to slow down development, jeopardizing food supply and aggravating rural poverty (FAO 2002). Strategies to mitigate losses due to lack of water have been adopted, aiming at the study and development of tolerant genotypes (genetic improvement) and products known as biostimulants which, when applied to plants, induce tolerance to water deficit (Souza et al. 2014; Calvo et al. 2014; Patrick 2015; Martins et al. 2018).

In this context, chitosan, consisting of $\mathrm{N}$-acetylglucosamine and glucosamine units, has been shown to have several benefits for agriculture due to its biological properties, high biodegradability, biocompatibility, low toxicity, renewable source, and high abundance (Badawy and Rabea 2011). Chitosan is the main chitin derivative and is obtained by its partial (up to 50\%) or total deacetylation. Chitosan has three reactive groups (susceptible to substitutions), which are the primary hydroxyl at carbon 6 , the secondary hydroxyl at carbon 3 and the amino group at carbon 2. Each of these chemical groups can undergo chemical (semisynthesis) modifications, that may alter physical, mechanical, and biological properties. It is worth mentioning that the amino group is generally more chosen, because it is more reactive than the hydroxyl groups and is available at high amounts in chitosan, which has a high degree of deacetylation (lower amount of acetyl groups bound to the amine group) (Jayakumar et al. 2008; Badawy and Rabea 2011).

Chitosan can increase plant growth and development under normal conditions and water deficit, positively changing several characteristics. The application of the biopolymer led to an increase in plant height, number of shoot branches, number of leaves, leaf area, biomass attributes and grain yield in several plant species such as maize (Guan et al. 2009; Lizárraga-Paulín et al. 2011; Mondal et al. 2013; Martins et al. 2018), beans (Ibrahim and Ramadan 2015), soybeans (Lee and Chung 2005), wheat (Wang et al. 2015), rice (Boonlertnirun et al. 2007; Pongprayoon et al. 2013; Chamnanmanoontham et al. 2015), millet (Sharathchandra et al. 2004), coffee (Dzung et al. 2011), among others. There is still little research on the use of these biopolymers in the stimulation of physiological responses to water stress tolerance. Results from the last decades have indicated that chitosan has the potential to be developed as an antitranspirant in agricultural stress situations, inducing tolerance to water deficit through increased water use efficiency (WUE, reduced water loss per fixed carbon) and/or higher defense against reactive oxygen species (Iriti et al. 2009; Zeng and Luo 2012; Pongprayoon et al. 2013; Sharp 2013).

Most of the studies involving chitosan derivatization are directed to biological activity with medical applications, as well as agricultural applications, to prevent pests and diseases (Laranjeira and Fávere 2009; Ramírez et al. 2010), but the capacity to induce tolerance to water deficit is poorly explored. In this context, the objective of this research was to synthesize two chitosan derivatives and characterize their effects on chlorophyll photosynthesis and fluorescence in maize hybrids sensitive to drought. The rationality involved in the proposal of the derivatives is that the addition of the $\mathrm{N}$-succinyl (SUC derivative) and $\mathrm{N}, \mathrm{O}$-dicarboxymethyl (MCA derivative) groups to the chitosan structure could increase its solubility in water and, due to the greater bioavailability in the plant, increase activity as a tolerance inducer to water stress.

\section{Materials and Methods}

\section{Synthesis of $N$-Succinyl (SUC) and N,O-Dicarboxymethyl (MCA) Chitosan Derivatives}

The chitosan used to obtain the derivatives has a percentage of deacetylation (DDA\%) of 63.5\% (Martins et al. 2018). The structure of the derivatives and chitosan is shown in Fig. 1. Both synthesized derivatives have chains with carboxylic acid groups, which were inserted into the starting chitosan via their amine (SUC) or amine + hydroxyl (MCA) groups.

For the semisynthesis of SUC ( $\mathrm{Li}$ and Ding 2014), $1 \mathrm{~g}$ chitosan (Galena Química e Farmacêutica Ltda) was dissolved under magnetic stirring and room temperature in $100 \mathrm{~mL}$ of $1 \%(\mathrm{v} / \mathrm{v})$ glacial acetic acid solution. Subsequently, a solution of succinic anhydride $(1.8 \mathrm{~g})$ in $99.9 \%$ acetone $(20 \mathrm{~mL})$ was added dropwise and still under stirring. The mixture formed was subjected to ultrasonic irradiation of $40-50 \mathrm{~Hz}$ in a bath at $50{ }^{\circ} \mathrm{C}$ for $60 \mathrm{~min}$. The resulting solution was then cooled to room temperature; $95 \%$ hydrated ethyl alcohol $(100 \mathrm{~mL})$ was added, and the mixture was transferred to a freezer $\left(-20^{\circ} \mathrm{C}\right)$, where it remained for $24 \mathrm{~h}$. After this period, $1 \mathrm{~mol} \mathrm{~L}^{-1}$ aqueous sodium hydroxide solution was added until $\mathrm{pH} 10$. Subsequently, acetone was added until precipitation occurred as a whitish caseous mass. The mixture was again conditioned in a freezer for $48 \mathrm{~h}$. After this period, the product was vacuum-filtered using 95\% ethyl alcohol (about $1000 \mathrm{~mL}$ ) to wash the retained solid, which was stirred with a glass stick throughout the cleaning process. The final product was obtained as an amorphous, coarse and yellowish-white solid after drying in a desiccator under vacuum and protected from light. Using 


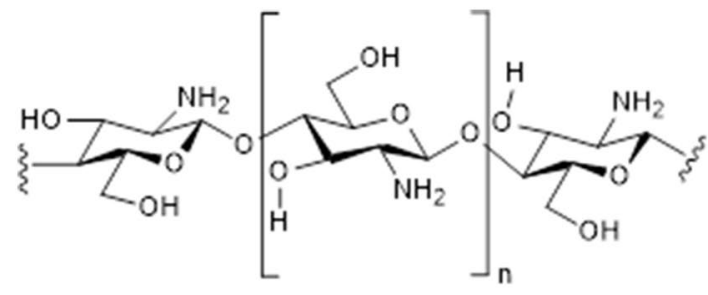

1
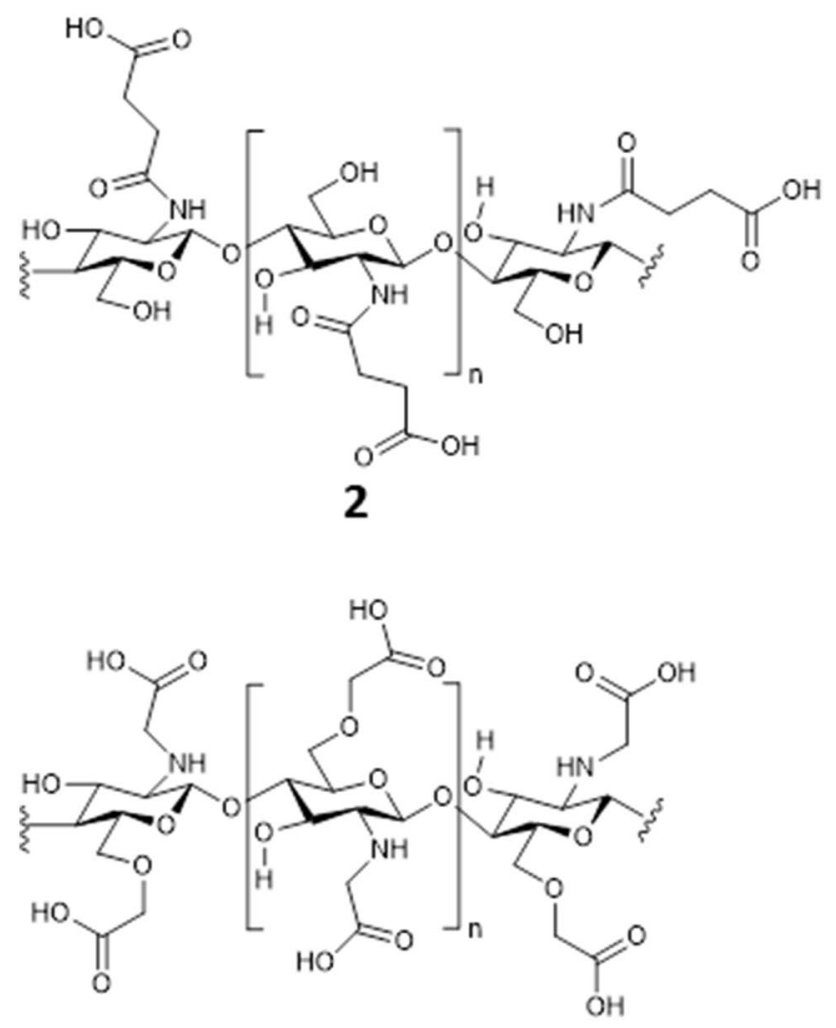

3

Fig. 1 Chemical structure of chitosan (1), of the $N$-succinyl derivative (2) and of the $\mathrm{N}, \mathrm{O}$-dicarboxymethyl derivative (3)

the same procedure, additional quantities of the product were obtained.

For the semisynthesis of MCA (Liu et al. 2001), $5 \mathrm{~g}$ chitosan was added to $99.9 \%$ isopropyl alcohol $(60 \mathrm{~mL})$ under magnetic stirring at room temperature. An aqueous sodium hydroxide solution $(12 \mathrm{~mL})$ was then added at $10 \mathrm{~mol} \mathrm{~L}^{-1}$, divided into five portions, over a period of $25 \mathrm{~min}$. The mixture was magnetically stirred for $30 \mathrm{~min}$ at room temperature. Subsequently, monochloroacetic acid $(30 \mathrm{~g})$ was added, divided into five portions over $5 \mathrm{~min}$. The formed mixture was heated at $70{ }^{\circ} \mathrm{C}$ with magnetic stirring for $3 \mathrm{~h}$. The reaction mixture was then cooled and the obtained solid product was vacuum-filtered and washed with absolute methanol
$(100 \mathrm{~mL})$. The product was rapidly oven-dried at $60{ }^{\circ} \mathrm{C}$, which resulted in a yellow solid. Additional quantities of the product were obtained using the same procedure.

\section{Local Conditions, Plant Material, and Experimental Design}

The experiment was conducted in a greenhouse located at Embrapa Milho and Sorgo, in the city of Sete Lagoas-MG (latitude $19^{\circ} 28^{\prime} \mathrm{S}$, longitude $44^{\circ} 15^{\prime} 08^{\prime \prime} \mathrm{W}$ and $732 \mathrm{~m}$ altitude). The average temperatures recorded during the evaluation period were as follows: maximum $36.3{ }^{\circ} \mathrm{C}$ and minimum $17.6{ }^{\circ} \mathrm{C}$. Relative air humidity ranged from 72 to $40 \%$. Two plants were used per 20-L pot, pre-filled with Typical Dystrophic Red Latosol. Fertilization was performed according to the soil chemical analysis recommendation, applying $10 \mathrm{~g}$ of $08-28-16$ per $20 \mathrm{~kg}$ of soil at planting. The cover was applied using $6 \mathrm{~g}$ of ammonium sulfate per pot at 30 and 60 days after planting. The plants were regularly irrigated, maintaining a good soil moisture until stress imposition. All phytosanitary treatments required for cultivation were performed. The plant material used was the hybrid BRS 1030, from the Embrapa Breeding Program and characterized as drought-sensitive (Souza et al. 2013a, 2014). Three seeds were planted per pot and, after germination, thinning was done, thus leaving two plants per pot.

The experimental design was completely randomized (CRD), comprising 5 conditions (irrigated control-IC, stressed control-SC, stressed with chitosan- $\mathrm{SC}+\mathrm{CHI}$, stressed with SUC-SC+SUC, stressed with MCA$\mathrm{SC}+\mathrm{MCA}$ ) and 6 replicates, totaling 30 pots.

\section{Stress Imposition and Application of Chitosan and Derivatives}

Soil water potential was monitored daily in the morning and afternoon (9.00 a.m. and 3.00 p.m.), with the aid of a tensiometer (Watermark 200SS, Irrometer, California, USA), installed in the center of the pots of each replicate, at a depth of $20 \mathrm{~cm}$. These sensors detect the ground water voltage based on the electrical resistance and were coupled to digital meters (Watermark meter) from the same company. Values ranged from $0 \mathrm{MPa}$ (totally wet) to $-2.00 \mathrm{MPa}$ (totally dry). Water was replaced based on the readings obtained with the sensor and it was returned to field capacity (CC) during the period that preceded the treatments. These calculations were performed with the aid of a spreadsheet, made according to the water retention curve of the soil.

When the plants reached the pre-flowering stage, treatments were imposed. The irrigated treatment consisted of daily irrigation until the soil reached a moisture close to field capacity (soil water tension of approximately $-0.18 \mathrm{MPa}$ ) whereas, for non-irrigated treatments, irrigation was 
performed applying $50 \%$ of the total water available, that is, until the water tension in the soil reached $-1.38 \mathrm{MPa}$, whose value corresponds to the soil specified.

When the plants reached the planned water stress (soil water tension of $-1.38 \mathrm{MPa}$ ), chitosan, as well as SUC and MCA derivatives, were sprayed at a concentration of $0.5 \mathrm{mg}$ plant $^{-1}$ through a pressurized $\left(\mathrm{CO}_{2}\right)$ costal sprayer $\left(2.15 \mathrm{~kg} \mathrm{f} \mathrm{cm}^{2}\right)$, equipped with a XR-Teejet $110.02 \mathrm{VS} \mathrm{noz-}$ zle, spraying the equivalent to $120 \mathrm{~L} \mathrm{ha}^{-1}$. The water deficit was maintained for 15 days. The analyses were performed $24 \mathrm{~h}$ after spraying (1DAA), at the end of the water stress period ( 15 days of stress, 15DAA), and $24 \mathrm{~h}$ after water reestablishment (rehydration), in which the soil returned to irrigation until reaching values close to those of field capacity. During this period, the following variables were analyzed: leaf water potential, leaf gas exchange, chlorophyll fluorescence, and contents of chlorophyll $a, b$ and carotenoids.

\section{Leaf Water Potential and Gas Exchange Measurements}

Leaf water potential was determined through a Scholander pressure chamber (PMS Instrument Company, Model 1000, Albany SE, USA), in four fully expanded leaves per replicate. Average water potential (midday, $\Psi_{\mathrm{md}}$ ) was measured at $12 \mathrm{p} . \mathrm{m}$. Unlike the other parameters, the first water potential analysis was performed only on the seventh day after application (7DAA).

Gas exchange was measured through a portable photosynthesis system (IRGA, LI-6400 XT, Li-Cor, Lincoln, Nebraska, USA). All measurements were taken in the morning, between 8.00 and 11.00 in a fully expanded leaf (ear leaf). The variables evaluated were photosynthetic rate $\left(P_{\mathrm{n}}\right)$, stomatal conductance $\left(g_{\mathrm{s}}\right)$, transpiration $(E)$, intercellular $\mathrm{CO}_{2}$ concentration $\left(C_{\mathrm{i}}\right)$, water use efficiency (WUE), internal carbon/external carbon ratio $(\mathrm{Ci} / \mathrm{Ca})$, and carboxylation efficiency (CE). Measurements were taken in a leaf area of $6 \mathrm{~cm}^{2}$, with controlled $\mathrm{CO}_{2}$ flux at a concentration of $380 \mu \mathrm{mol} \mathrm{CO} \mathrm{mol}^{-1}$ air. The photon flux density (PPFD) was $1500 \mu \mathrm{mol} \mathrm{m} \mathrm{m}^{-2} \mathrm{~s}^{-1}$ with blue-red LED light source (6400-02B LED) and controlled leaf temperature $\left(30^{\circ} \mathrm{C}\right)$.

\section{Chlorophyll Fluorescence Measurements}

In the measurement of chlorophyll $a$ fluorescence parameters, a Mini-PAM modulated fluorometer was used (Heinz Walz, Effeltrich, Germany). After a 30-min adaptation in the dark, the minimum fluorescence $\left(F_{0}\right)$ was measured with sufficiently low light, avoiding photochemical reactions; maximum fluorescence $(F \mathrm{~m})$ was measured applying a saturating light pulse of $7000 \mu \mathrm{m}$ photons $\mathrm{m}^{-2} \mathrm{~s}^{-1}$ for $0.8 \mathrm{~s}$. In the samples adapted in the dark, the maximum efficiency of the photosystem (PSII) was estimated by the $F \mathrm{v} / F \mathrm{~m}$ ratio. The leaves were then illuminated with actinic light with an intensity of
$1500 \mu \mathrm{mol}$ photons $\mathrm{m}^{-2} \mathrm{~s}^{-1}$. Constant fluorescence $(F \mathrm{~s})$ was obtained and another saturating light pulse was then applied for $1 \mathrm{~s}$ to obtain the maximum fluorescence emitted by the leaves $\left(F \mathrm{~m}^{\prime}\right)$. The actinic light was removed and the leaves were irradiated with far-red light for the obtention of lightadapted $F_{\mathrm{O}}\left(F_{\mathrm{O}^{\prime}}\right)$. Photochemical quenching was calculated as $q P=\left(F \mathrm{~m}^{\prime}-F \mathrm{~s}\right) /\left(F \mathrm{~m}^{\prime}-F \mathrm{o}^{\prime}\right)$, and non-photochemical quenching was calculated as $N P Q=\left(F \mathrm{~m}-F \mathrm{~m}^{\prime}\right) / F \mathrm{~m}^{\prime}$. Other parameters were also evaluated, such as electron transport rate $(E T R)=\left(F \mathrm{~m}^{\prime}-F \mathrm{~s} / F \mathrm{~m}^{\prime}\right) \times \mathrm{PPFD} \times 0.5 \times 0.84$; Effective photochemical quantum yield of PS II (YII) $=F \mathrm{~m}^{\prime}-F \mathrm{~s} / F \mathrm{~m}^{\prime}$ $=\Delta F / F \mathrm{~m}^{\prime}$, quantum yields of regulated energy dissipation of PSII $(\mathrm{YNPQ})=F \mathrm{~s} / F \mathrm{~m}^{\prime}-F \mathrm{~s} / F \mathrm{~m}$, quantum yields of non-regulated energy dissipation of PSII $(\mathrm{YNO})=F \mathrm{~s} / F \mathrm{~m}$ (van Kooten and Snel 1990; Genty et al. 1996).

\section{Chlorophyll $\boldsymbol{a}, \boldsymbol{b}$ and Carotenoids}

Chlorophylls and carotenoids were extracted from $100 \mathrm{mg}$ of leaf tissue macerated in mortar and pistil in the presence of $3.0 \mathrm{~mL}$ of $80 \%$ acetone (Arnon 1949) for $5 \mathrm{~min}$, followed by filtration, a procedure repeated three times with the residue that remained in the filter paper. The filtrate was mixed and centrifuged at $3500 \mathrm{rpm}$ for $20 \mathrm{~min}$. The final volume was adjusted to $10 \mathrm{~mL}$ with distilled water. During the procedure, the tubes were protected from light with aluminum foil. Readings, taken at 470 (A470), 647 (A647), and $663 \mathrm{~nm}$ (A663), as well as the concentrations of chlorophyll $a, b$ and total carotenoids, were calculated by the following equations:

$$
\begin{aligned}
& \text { Chlorophyll } a(\mu \mathrm{g} / \mathrm{mL}): 12.25 \text { A663 - 2.79 A647 } \\
& \text { Chlorophyll } b(\mu \mathrm{g} / \mathrm{mL}): 21.50 \text { A647 - 5.10 A663 } \\
& \text { Carotenoids }(\mu \mathrm{g} / \mathrm{mL}):(1000 \text { A470 - } 1.82 \\
& [\mathrm{Cl} a]-85.02[\mathrm{Cl} b]) / 198
\end{aligned}
$$

\section{Data Analysis}

The means \pm standard error (SE) was calculated for each parameter. For the statistical analysis of the results, a comparison among treatments was performed each day after application $(1 \mathrm{DAA}=1$ day after application, $15 \mathrm{DAA}=15$ days after application and rehydration); analysis of variance (ANOVA) and the Scott Knott test at $0.05 \%$ significance $(P \leq 0.05)$ were run, using 4.3 Sisvar software (version 4.3, Universidade Federal de Lavras, Lavras, Brasil).

\section{Results}

\section{Analysis of Water Potential and Gas Exchange}

The analysis of variance for water potential ( $\Psi \mathrm{MPa})$ and gas exchange [photosynthetic rate $\left(P_{\mathrm{n}}\right)$, stomatal 
conductance $\left(g_{\mathrm{s}}\right)$, intercellular $\mathrm{CO}_{2}$ concentration $\left(C_{\mathrm{i}}\right)$, water use efficiency (WUE), carboxylation efficiency $(\mathrm{CE})$ ], was significant $(P \leq 0.05)$. At 7 and 15 days of water deficit, in general, the plants that underwent this stress, as expected, had lower water potentials than those normally irrigated during the whole evaluation period (Fig. 2a). However, when rehydrated, plants under water deficit and treated with SUC (SC + SUC) and MCA (SC+MCA) showed a better recovery capacity, with higher water potential values, even higher than those obtained by the irrigated control (IC) (Fig. 2a).

For the photosynthetic rate $\left(P_{\mathrm{n}}\right)$ on the first day of stress (1DAA), the treatments that received chitosan and the derivatives showed a decrease rate (Fig. 2b). However, at 15 days of stress (15DAA), the application of MCA $(\mathrm{SC}+\mathrm{MCA})$ led to a higher photosynthetic rate in relation to the treatment that did not receive the molecules (SC) and received chitosan $(\mathrm{SC}+\mathrm{CH})(\mathrm{Fig} .2 \mathrm{~b})$ and the derivative SUC (SC + SUC). In rehydration, the photosynthetic rate of treatments with chitosan and derivatives returned to values similar to the control (irrigated control-IC), except for the stressed control (SC) treatment.

On the first day of stress (1DAA), treatments with chitosan and MCA led to a decrease in stomatal conductance $\left(g_{\mathrm{s}}\right)$ in relation to the stressed control (SC) treatment. The derivatives SUC and MCA stood out at the end of the stress period (15DAA), with higher $g_{\mathrm{s}}$ averages. In rehydration, these treatments presented lower conductance in relation to the controls (IC and SC) (Fig. 2c).

Maize plants treated with chitosan + SUC obtained higher $C_{\mathrm{i}}$ on the first (1DAA) and fifteenth (15DAA) days of stress. The derivative MCA showed $C_{\mathrm{i}}$ similar to the controls at the end of the stress period (15DAA). In the rehydration phase of the plants, all the treatments with the addition of molecules were statistically equal and inferior to the controls, irrigated and non-irrigated (Fig. 2d).

Regarding water use efficiency (WUE), on the first day of stress (1DAA), the treatment with the MCA molecule had higher averages, when compared to the other treatments. The same result was observed in plant rehydration (Fig. 2e).

On the first day after application (1DAA), plants that received the treatment with chitosan and its derivatives had lower carboxylation efficiency $\left(P_{\mathrm{n}} / C_{\mathrm{i}}\right)$ in relation to the controls (IC and SC). At the end of the water stress period, the hybrid BRS 1030 had higher $P_{\mathrm{n}} / C_{\mathrm{i}}$ in plants sprayed with chitosan and SC + MCA and, after water reestablishment, plants treated with chitosan, SUC and MCA were statistically superior to the other treatments for the variable under study (Fig. 2f).

\section{Chlorophyll Fluorescence}

During the first day of evaluation (1DAA), plants treated with MCA were higher than the other treatments for the effective photochemical quantum yield of PS II (YII) $(P \leq 0.05)$ (Fig. 3a). At 15 days of water stress (15DAA), the same response was observed, with a higher YII for SUC $(\mathrm{SC}+\mathrm{SUC})$ and MCA $(\mathrm{SC}+\mathrm{MCA})$ molecules. The results of the electron transport rate (ETR) followed the same trend found for the effective quantum yield of PSII (YII), and the treatments SC + SUC and SC + MCA had higher ETR, similar to the irrigated control (IC), throughout stress and rehydration (Fig. 3b).

On the first day after application (1DAA), the irrigated control (IC) and the SUC derivative showed higher photochemical quenching $(q P)$. At 15 days of water stress (15DAA) and rehydration, there was no difference among treatments (Fig. 3c).

Regarding the non-photochemical quenching (NPQ), on the first day after the application of chitosan and its derivatives (1DAA), there was no statistical difference among treatments (Fig. 3d). On the other hand, at the end of the stress period (15DAA), only the application of MCA induced a decrease in NPQ but, in rehydration, this derivative showed higher non-photochemical quenching (Fig. 3d).

There was only a reduction in the quantum yields of regulated energy dissipation of PSII (YNPQ) with the water stress treatment (SC) on 1DAA, but the applications did not modify this parameter at 15DAA and rehydration (Fig. 4a). However, the application of SUC and MCA decreased the quantum yields of non-regulated energy dissipation of PSII (YNO) at the beginning of stress (1DAA) (Fig. 4b). In the rehydration process, the MCA derivative still decreased the YNO.

The use of SUC and MCA was responsible for lower initial fluorescence $(F \mathrm{o})$ at 15DAA and rehydration (Fig. 4c). On the first day of stress and at 15 days (1DAA and 15DAA), there were no differences among treatments for the maximum efficiency of photosystem (PSII) $(F \mathrm{v} / F \mathrm{~m})($ Fig. $4 \mathrm{~d})$.

\section{Analysis of Chlorophyll Contents}

In the chlorophyll content analysis, it was observed that, in all pigments (except chlorophyll $b$ ), the application of chitosan followed by the derivatives showed higher averages, when compared to the non-irrigated control (Table 1). 

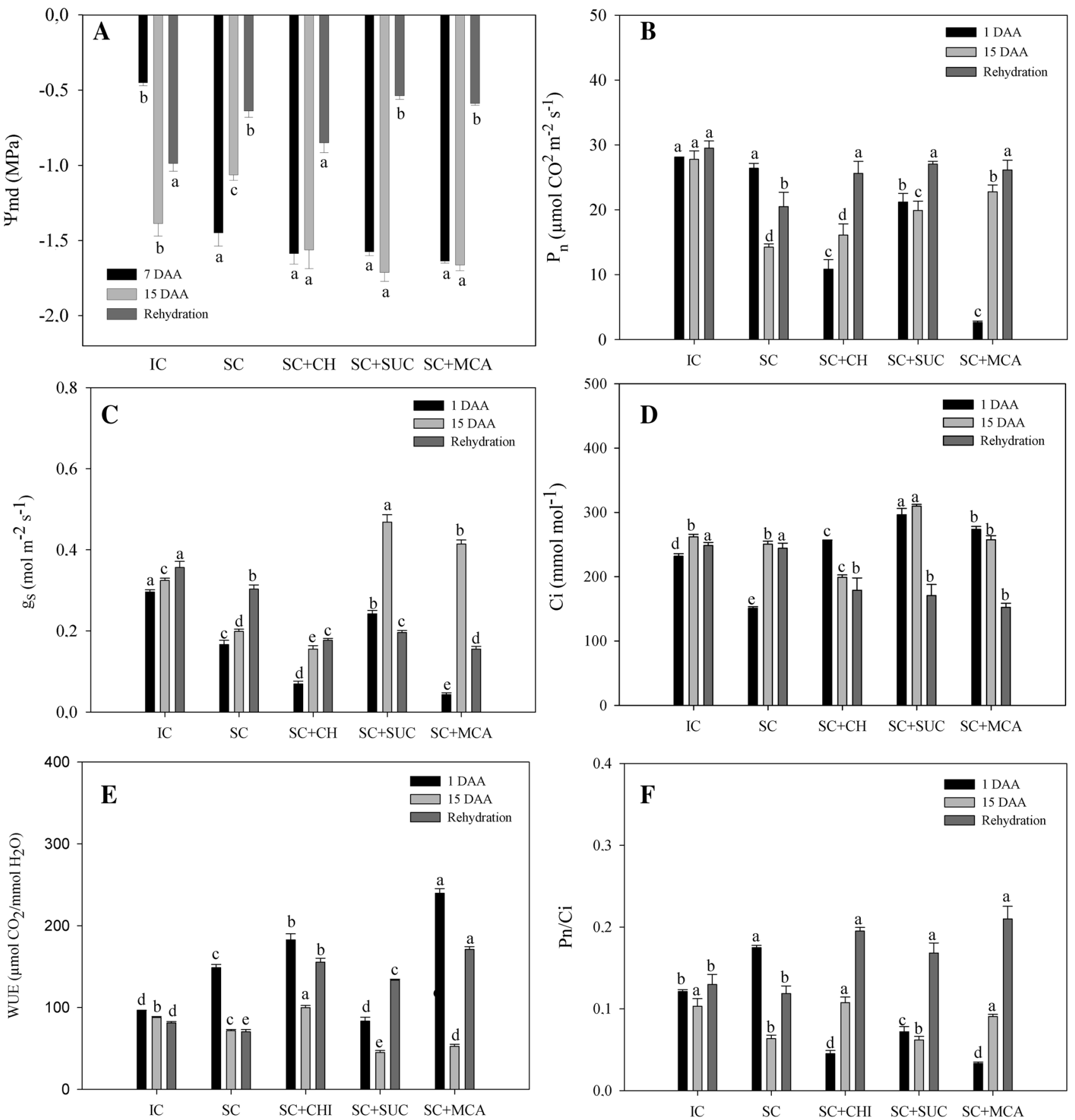

Fig. 2 a Average leaf water potential $\left(\Psi_{\mathrm{md}}\right)$ and gas exchange parameters during stress imposition and water recovery in the BRS 1030 maize hybrid, with the application of chitosan and its derivatives. b Photosynthetic rate $\left(P_{\mathrm{n}}\right)$, c stomatal conductance $\left(g_{\mathrm{s}}\right)$, d intercellular $\mathrm{CO}_{2}$ concentration $\left(C_{\mathrm{i}}\right)$, e water use efficiency (WUE), f carboxylation efficiency (CE). Means followed by the same let-

\section{Discussion}

According to Boyer (1970), the maximum photosynthesis occurs with leaf water potentials between -0.6 and $-0.8 \mathrm{MPa}$. Chitosan derivatives provided a good water

ter among treatments on each day after application (1DAA; 7DAA; 15DAA; rehydration) do not differ by the Scott-Knott test at $5 \%$ probability $(P \leq 0.05) . I C$ irrigated control, $S C$ stressed control, $S C+C H I$ stressed with chitosan, $S C+S U C$ stressed with SUC, $S C+M C A$ stressed with MCA. Bars correspond to \pm standard error (SE) $(n=6)$

recovery capacity potential for plants when they returned to normal irrigation, as shown in Fig. 2a, b. The potentials are within the range mentioned by Boyer (1970), and the photosynthesis data also followed that observed; it was greater during rehydration. 

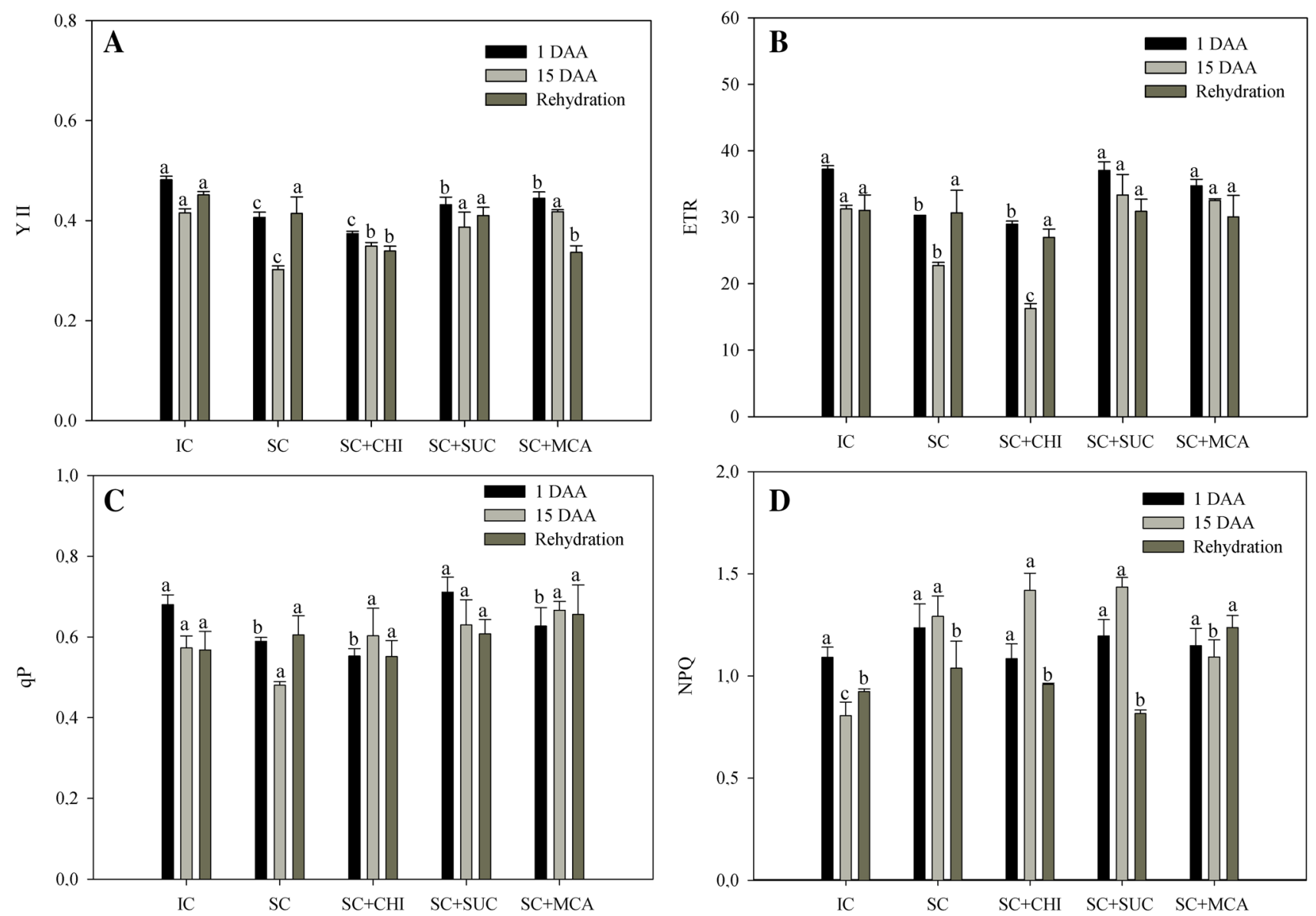

Fig. 3 Chlorophyll fluorescence parameters during stress imposition and water recovery in the BRS 1030 drought-sensitive maize hybrid, with the application of chitosan and its derivatives. a Effective photochemical quantum yield of PS II (YII), b electron transport rate $(E T R)$, c photochemical quenching $(q P)$, d non-photochemical quenching $(N P Q)$. Means followed by the same letter among treat-

ments on each day after application (1DAA; 15DAA; rehydration) do not differ by the Scott-Knott test at $5 \%$ probability $(P \leq 0.05)$. IC irrigated control, $S C$ stressed control, $S C+C H I$ stressed with chitosan, $S C+S U C$ stressed with SUC, $S C+M C A$ stressed with MCA. Bars correspond to \pm standard error (SE) $(n=6)$

One of the first responses that occurs under exposure to drought is stomatal closure, followed by a decrease in photosynthetic rate $\left(P_{\mathrm{n}}\right)$ (Souza et al. 2013b). Thus, maize plants submitted to water deficit, which were treated with chitosan derivatives, underwent stomatal closure at the beginning of stress, which resulted in a decrease in stomatal conductance $\left(g_{\mathrm{s}}\right)$ and, consequently, in photosynthetic rate $\left(P_{\mathrm{n}}\right)$. Research points to chitosan as an antitranspirant in the first hours of stress, acting in stomatal closure (Pospisilova 2003; Iriti et al. 2009). The treatments in which the derivatives and chitosan were applied increased this response at the beginning of water stress. This increase may be important for adapting maize plants at the onset of stress, because it is a drought tolerance mechanism (Yao et al. 2013). This decrease in conductance and transpiration by chitosan is induced by chemical $\mathrm{H}_{2} \mathrm{O}_{2}$ messengers and $\mathrm{ABA}$, which limit gas exchange (Lee et al. 1999; Iriti et al. 2009; Khokon et al. 2010; Pongprayoon et al. 2013). Therefore, the MCA derivative appears

to be inducing more than the chitosan itself, the production of $\mathrm{ABA}$ and other messengers in the first $24 \mathrm{~h}$. Even more interesting is the performance of the two derivatives (mainly MCA) after 15 days of stress (15DAA), which significantly increased gas exchange $\left(P_{\mathrm{n}}, g_{\mathrm{s}}\right.$, WUE), when compared to chitosan and the stressed control (SC). An increase in photosynthesis and stomatal conductance was also observed in the application of chitosan in soybean and maize by Khan et al. (2002). Genetic variability for water deficit tolerance was found in maize cultivars with higher photosynthetic rates $\left(P_{\mathrm{n}}\right)$ and stomatal conductance $\left(g_{\mathrm{s}}\right)$ in the face of extended water stress (Carvalho et al. 2011; Souza et al. 2013b). It is also worth mentioning that the application of the molecules resulted, at the end of stress (15DAA), in greater stomatal conductance, even with the decrease in water status $\left(\Psi_{\mathrm{md}}\right)$ (Fig. 2a, b). This behavior of plants with lower water status (remaining with open stomata) could be explained by a leaf osmotic adjustment optimized by chitosan molecules. Li 

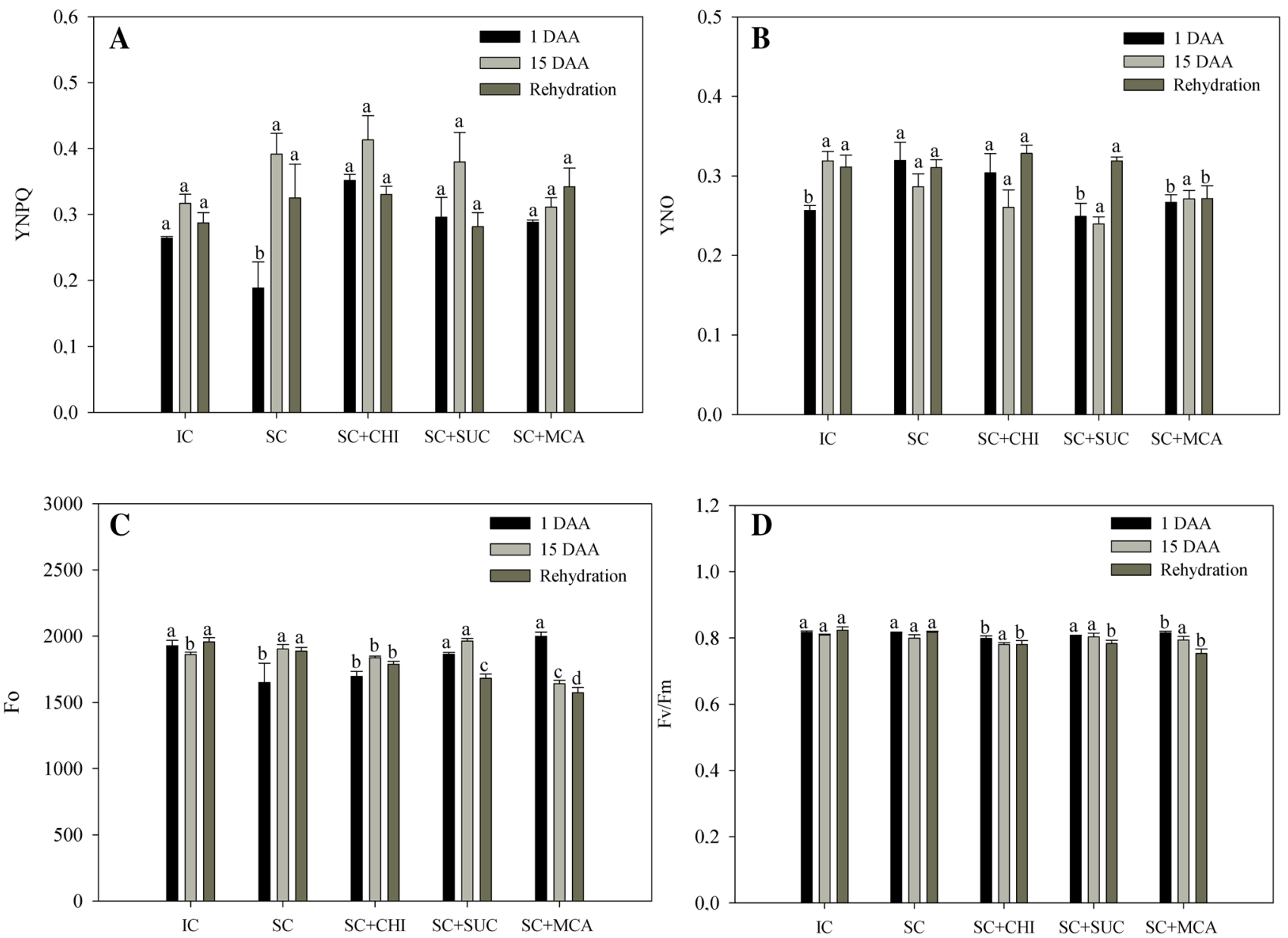

Fig. 4 Chlorophyll fluorescence parameters during stress imposition and water recovery in the BRS 1030 drought-sensitive maize hybrid, with the application of chitosan and its derivatives. a Quantum yields of regulated energy dissipation of PSII (YNPQ), b quantum yields of non-regulated energy dissipation of PSII (YNO), $\mathbf{c}$ initial fluorescence $-F \mathrm{O}$, d maximum efficiency of PSII (PSII) $-F \mathrm{v} / F \mathrm{~m}$. Means

Table 1 Contents of chlorophyll $a$ (CHL A) and $b$ (CHL B); chlorophyll $a+b$ (CHL $\mathrm{A}+\mathrm{CHL} \mathrm{B})$ and xanthophylls + carotenoids (XANT + CARO), after 15 days of water deficit in maize hybrid BRS1030, sprayed or not with chitosan $(\mathrm{CH})$ and its derivatives (SUC and MCA)

\begin{tabular}{llllc}
\hline Treatment & CHL A & CHL B & CHL A + CHL B & XANT + CARO \\
\hline IC & $0.5066 \mathrm{~B}$ & $0.1100 \mathrm{D}$ & $0.6533 \mathrm{~B}$ & $10.2266 \mathrm{C}$ \\
$\mathrm{SC}$ & $0.2500 \mathrm{D}$ & $0.2300 \mathrm{~A}$ & $0.4400 \mathrm{D}$ & $7.4566 \mathrm{D}$ \\
SC+CH & $0.6066 \mathrm{~A}$ & $0.2000 \mathrm{~B}$ & $0.8233 \mathrm{~A}$ & $19.6566 \mathrm{~A}$ \\
SC+SUC & $0.4133 \mathrm{C}$ & $0.1466 \mathrm{C}$ & $0.5500 \mathrm{C}$ & $12.3800 \mathrm{~B}$ \\
SC+MCA & $0.3900 \mathrm{C}$ & $0.1733 \mathrm{C}$ & $0.5800 \mathrm{C}$ & $11.3666 \mathrm{C}$ \\
\hline
\end{tabular}

*Means followed by the same vertical letter do not differ by the ScottKnott test at $5 \%$ probability $(P \leq 0.05)$

IC irrigated control, $S C$ stressed control, $S C+C H I$ stressed with chitosan, $S C+S U C$ stressed with SUC, $S C+M C A$ stressed with MCA

followed by the same letter among treatments on each day after application (1DAA; 15DAA; rehydration) do not differ by the Scott-Knott test at $5 \%$ probability $(P \leq 0.05)$. IC irrigated control, $S C$ stressed control, $S C+C H I$ stressed with chitosan, $S C+S U C$ stressed with SUC, $S C+M C A$ stressed with MCA. Bars correspond to \pm standard error (SE) $(n=6)$

et al. (2017) verified that chitosan can influence the metabolism of osmoregulatory sugars in white clover (Trifolium repens).

This induction of tolerance in maize by the significant increase in photosynthesis (gas exchange and photochemical reactions) by chitosan derivatives may have happened due to the performance of these molecules in processes at the physiological and molecular level of the leaves as an increase in the defense mechanisms against reactive oxygen species (ROS) (Sharp 2013; Katiyar et al. 2015) or by the performance in nucleus and chloroplast genes involving the photosynthetic process (Chamnanmanoontham et al. 2015). Several studies show that chitosan doses sprayed on the leaves result in lower lipid peroxidation (membrane stability), a higher antioxidant enzymatic activity, and higher content of non-enzymatic antioxidant compounds (ascorbic acid, phenolic compounds, and others) under water deficit 
conditions (Yang et al. 2009; Povero et al. 2011; Mondal et al. 2012; Karimi et al. 2012; Choudhary et al. 2017; Pirbalouti et al. 2017). In Dendrobium sp., chitosan had its greatest action in chloroplasts (Limpanavech et al. 2008) and chitosan applied to rice positively increased the expression of proteins located mainly in the chloroplast, indicating that the main target of action of chitosan is this organelle (Chamnanmanoontham et al. 2015).

In this study, the derivatives and chitosan increased the intercellular $\mathrm{CO}_{2}$ concentration $\left(C_{\mathrm{i}}\right)$ at the beginning of stress. These results were also found by Iriti et al. (2009), studying chitosan application in beans at the beginning of water stress. These data corroborate the lower carboxylation efficiency $\left(P_{\mathrm{n}} / C_{\mathrm{i}}\right)$, which was also found in this study at the beginning of stress. This indicates that there may be some non-stomatal limitation involving the carboxylation enzymes of maize photosynthesis (Perdomo et al. 2017). Souza et al. (2013b) studied the same maize hybrid (BRS1030) and also observed a non-stomatal limitation in these plants under drought conditions. However, this non-stomatal limitation was reduced with treatment with MCA during stress in this study. At 15DAA, however, chitosan and MCA prevented the reduction in carboxylation efficiency, even with the same $P_{\mathrm{n}} / C_{\mathrm{i}}$ than the irrigated control.

An interesting fact is that the MCA derivative, in general, significantly potentiated water use efficiency (WUE) throughout stress, showing that this derivative induces a greater water saving by fixed carbon. This parameter is a great indicator of water stress tolerance in $\mathrm{C} 4$ plants such as maize (Araus et al. 2010; Lopes et al. 2011; Souza et al. 2013b; Hasan et al. 2017). In bean plants, chitosan with $85 \%$ deacetylation did not increase WUE (Iriti et al. 2009). The MCA derivative sprayed in this study still resulted in higher WUE in rehydration, a fact not yet evidenced in studies with foliar application of chitosan.

This characteristic of the BRS1030 maize hybrid, being sensitive to water deficit, can also be observed in this study by the values found for chlorophyll fluorescence parameters. Under drought conditions, the hybrid showed lower values for YII, qP, ETR in the stressed treatment (SC), corroborating other studies with sensitive genotypes (Souza et al. 2013b; Saglam et al. 2014). Ahmad et al. (2017), Zou et al. (2015), and Zhang et al. (2016) suggested in their study with Mentha piperita $\mathrm{L}$. and wheat that chitosan oligomers may play a role as elicitors in light use efficiency, due to the positive modifications of these molecules in chlorophyll fluorescence.

In maize, water deficit-tolerant genotypes tend to have a higher effective photochemical quantum yield of PS II (YII) (Ding et al. 2005; O'Neill et al. 2006; Souza et al. 2013b) and chitosan derivatives yielded higher values for this parameter, inducing a certain tolerance to the BRS1030 maize hybrid. The lack of water in maize plants (stressed control) induces a decrease in the "opening" of reaction centers of photosystem II, as measured by the photochemical quenching $(q P)$. Drought-sensitive genotypes tend to have lower maintenance of water status (Efeoglu et al. 2009; Carvalho et al. 2011; Souza et al. 2013b), resulting in lower values of $q P$, but the use of chitosan and its derivatives has been found to have reversed these values (Table 1).

In treatments stressed with the application of SUC and MCA, the increase in photosynthesis $\left(P_{\mathrm{n}}\right)$ corroborated the increase of YII and ETR, confirming the action target of these molecules in the photosynthetic capacity by increasing electron transport yield in PSII.

The NPQ is involved in the dissipation of excess energy and the regulation of the reaction center of photosystem II (PSII) and, in maize, this can be an important parameter to indicate photoprotective mechanisms (Yan et al. 2017). The NPQ data in this study did not show differences, corroborating the results found by Iriti et al. (2009). However, the division of non-photochemical quenchings (YNPQ and YNO) makes clear the role of chitosan derivatives in the partitioning process of the light energy absorbed by the photosynthetic apparatus. SUC and MCA derivatives lead, at the beginning of stress, to a decrease in YNO, YNPQ maintenance and YII increase, indicating that the excess excitation energy is safely dissipated at the antenna level and that the photosynthetic energy fluxes are well regulated in these treatments, without resulting in photodamage due, for example, to ROS.

When there is no stress, under normal photosynthetic conditions, the absorbed light is first used for photosynthesis, whereas only a small portion is transformed into chlorophyll heating or fluorescence (Rinderle and Linchitenthaler 1988). Increases in the minimum level of fluorescence $\left(F_{0}\right)$ would be related to negative effects on photosynthesis, as they lead to a reduction in excitation energy transfer from the PSII antenna complex to the reaction centers. The application of MCA did not lead to this increase. Peltier and Cournac (2002) related $F_{0}$ with quinone redox (QA), the first PSII acceptor.

The values of maximum efficiency of PSII $(F \mathrm{v} / F \mathrm{~m})$ indicate that there was no damage to the photosynthetic apparatus of the plants since, according to Kalaji and Guo (2008), $F \mathrm{v} / F \mathrm{~m}$ values should be lower than 0.70 , to be considered damage to the photosynthetic apparatus.

The decrease in chlorophyll content in maize under water deficit is well evidenced. Saglam et al. (2014) and Ghahfarokhi et al. (2015) observed in the drought experiment a decrease in chloroplastidic pigments in a susceptible maize cultivar and an increase in tolerant genotypes. In studies with the application of chitosan and a chitosan oligomer in leaves of coffee plants, Dzung et al. (2011) concluded that the application of these polymers increased the contents of chlorophyll $a, b$ and carotenoids in the leaves. In this study, 
the application of chitosan (mainly) and the derivatives increased the content of all pigments. According to Farouk and Amany (2012), chitosan should increase the endogenous levels of cytokinins that stimulate chlorophyll synthesis.

The MCA derivative, and also SUC, but to a lesser extent, improved the physiological characteristics and alleviated the effects of water stress in maize plants, when compared to pure chitosan. When chitosan is applied to the leaves and reaches the cell wall, enzymes such as chitinases are produced and this biopolymer is reduced to oligosaccharides (chitooligosaccharides), which are important signaling agents for plant cells (Hadwiger 2015; Malerba and Cerana 2016). These oligosaccharides arrive in the nucleus and in the chloroplastida, acting in cascade reactions inducing oxidative burst, change in $\mathrm{Ca}^{2+}$ influxes, production of hormones and phytoalexins, besides modifying chromatin and protein expression (Zeng et al. 2010; Zhang et al. 2011; Hadwiger 2013, 2015; Pichyangkura and Chadchawan 2015; Chamnanmanoontham et al. 2015). A possible reason for this response of the derivatives is that oligosaccharides from the cleavage by chitinases in MCA and SUC derivatives containing $\mathrm{N}$-succinyl and $\mathrm{N}, \mathrm{O}$-dicarboxymethyl groups, respectively, appear to be more active in potentiating photosynthetic responses in sensitive maize than the oligosaccharides originated only from chitosan, as they are more soluble in the physiological environment. This improves their bioavailability, leading to the cellular changes previously mentioned. Once chitosan contains more than $50 \%$ of its $\mathrm{NH}_{2}$ (carbon 2) groups deacetylated, it has high solubility when in aqueous acid solution, but not in pure water. Both the SUC and MCA derivatives are much more water-soluble than chitosan, as they contain carboxylic acid groups which facilitate the solvation process in water. It is also important to mention that, when in the physiological environment, these groups can further contribute to the solubilization process of the compound, because they may be ionized in the carboxylate form, which intensifies solubilization in aqueous media (Signini and Campana-Filho 2001).

\section{Conclusion}

The results of this study showed that the use of chitosan derivatives is positive for chlorophyll photosynthesis and fluorescence, affecting the mechanisms involved in them, such as stomatal activity, water use efficiency and photosystem II activity (PSII). Chitosan spraying with the addition of $N$-succinyl (SUC derivative) and $N, O$-dicarboxymethyl (MCA derivative) groups potentiated the activities as tolerance inducers to water stress.
Acknowledgements The authors would like to thank Fundação de Amparo à Pesquisa do Estado de Minas Gerais (FAPEMIG) and Conselho Nacional de Desenvolvimento Científico e Tecnológico (CNPq), for the master's degree scholarship (C. O. Reis) and project financing (APQ-00651-14)

Funding This study was funded by Fundação de Amparo à Pesquisa do Estado de Minas Gerais (FAPEMIG) and Conselho Nacional de Desenvolvimento Científico e Tecnológico. Project financing: APQ-00651-14.

\section{Compliance with Ethical Standards}

Conflict of interest The authors declare that they have no conflict of interest.

Research Involving Human and Animal Participants This article does not contain any studies with human participants (or animals) performed by any of the authors.

\section{References}

Ahmad B, Masroor M, Khan A, Jaleel H, Sadiq Y, Shabbir A, Uddin M (2017) Exogenously sourced $\gamma$-irradiated chitosan-mediated regulation of growth, physiology, quality attributes, and yield in Mentha piperita L. Turk J Biol 41:388-401. https://doi.org/10.3906/ biy-1608-64

Anjum SA, Farooq M, Wang LC, Xue LL, Wang SG, Wang L, Zhang S, Chen M (2011) Gas exchange and chlorophyll synthesis of maize cultivars are enhanced by exogenously-applied glycinebetaine under drought conditions. Plant Soil Environ 57:326-331

Araus JL, Sanchez C, Cabrera-Bosquet L (2010) Is heterosis in maize mediated through better water use? New Phytol 187:392-406. https://doi.org/10.1111/j.1469-8137.2010.03276.x

Arnon DI (1949) Copper enzymes in isolated chloroplasts polyphenoloxidase in Beta vulgaris. Plant Physiol 24:1-15. https://doi. org/10.1104/pp.24.1.1

Badawy MEI, Rabea EI (2011) A biopolymer chitosan and its derivatives as promising antimicrobial agents against plant pathogens and their applications in crop protection. Int $\mathrm{J}$ Carbohydr Chem 2011:1-29. https://doi.org/10.1155/2011/460381

Boonlertnirun S, Sarobol ED, Meechoui S, Sooksathan I (2007) Drought recovery and grain yield potential of rice after chitosan application. Kasetsart J Nat Sci 41:1-6

Boyer JS (1970) Leaf enlargement and metabolic rates in corn, soybean and sunflower at various leaf water potentials. Plant Physiol 46(2):233-235. https://doi.org/10.1104/pp.17.01677

Calvo P, Nelson L, Kloepper JW (2014) Agricultural uses of plant biostimulants. Plant Soil 383:3-41. https://doi.org/10.1007/s1110 4-014-2131-8

Carvalho RC, Cunha A, Silva JM (2011) Photosynthesis by six Portuguese maize during drought stress and recovery. Acta Physiol Plant 33:359-374. https://doi.org/10.1007/s11738-010-0555-1

Chamnanmanoontham N, Pongprayoon W, Pichayangkura R, Roytrakul S, Chadchawan S (2015) Chitosan enhances rice seedling growth via gene expression network between nucleus and chloroplast. Plant Growth Regul 75:101-114. https://doi.org/10.1007/s1072 5-014-9935-7

Choudhary RC, Kumaraswamy RV, Kumari S, Sharma SS, Pal A, Raliya R, Biswas P, Saharan V (2017) Cu-chitosan nanoparticle boost defense responses and plant growth in maize (Zea mays L.). Sci Rep 7:9754. https://doi.org/10.1038/s41598-017-08571-0 
Ding L, Wang KJ, Joang GM, Liu MZ, Niu SL, Gao LM (2005) Postanthesis changes in photosynthetic traits of maize hybrids released in different years. Field Crop Res 93:108-115. https:// doi.org/10.1016/j.fre.2004.09.008

Dzung NA, Khanh VTP, Dzung TT (2011) Research on impact of chitosan oligomers on biophysical characteristics, growth, development and drought resistance of coffee. Carbohydr Polym 84:751-755. https://doi.org/10.1016/j.carbpol.2010.07.066

Efeoglu B, Ekmekci Y, Cicek N (2009) Physiological responses of three maize cultivars to drought stress and recovery. S Afr J Bot 75:31-42. https://doi.org/10.1016/j.sajb.2008.06.005

FAO (2002) Deficit irrigation practices. Water reports, n. 22. Rome

Farouk S, Amany AR (2012) Improving growth and yield of cowpea by foliar application of chitosan under water stress. Egypt J Biol 14:14-26. https://doi.org/10.4314/ejb.v14i1.2

Genty B, Harbinson J, Cailly AL, Rizza F (1996) Fate of excitation at PS II in leaves: the non- photochemical side. Presented at: The Third BBSRC Robert Hill Symposium on Photosynthesis, March 31 to April 3, University of Sheffield, Department of Molecular Biology and Biotechnology, Western Bank, Sheffield, UK, pp 28

Ghahfarokhi MG, Mansurifar S, Taghizadeh-Mehrjardi R, Saeidi M, Jamshidi AM, Ghasemi E (2015) Effects of drought stress and rewatering on antioxidant systems and relative water content in different growth stages of maize (Zea mays L.) hybrids. Arch Agron Soil Sci 61(4):493-506. https://doi.org/10.1080/03650 340.2014.943198

Guan YJ, Hu J, Wang XJ, Shao CX (2009) Seed priming with chitosan improves maize germination and seedling growth in relation to physiological changes under low temperature stress. J Zhejiang Univ Sci 10:427-433. https://doi.org/10.1631/jzus.B0820373

Hadwiger LA (2013) Multiple effects of chitosan on plant systems: solid science or hype. Plant Sci 208:42-49. https://doi. org/10.1016/j.plantsci.2013.03.007

Hadwiger LA (2015) Anatomy of a nonhost disease resistance response of pea to Fusarium solani: PR gene elicitation via DNase, chitosan and chromatin alterations. Front Plant Sci 6:373. https://doi. org/10.3389/fpls.2015.00373

Hasan SA, Rabei SH, Nada RM, Abogadallah GM (2017) Water use efficiency in the drought-stressed sorghum and maize in relation to expression of aquaporin genes. Biol Plantarum 61(1):127-137. https://doi.org/10.1007/s10535-016-0656-9

Ibrahim EA, Ramadan WA (2015) Effect of zinc foliar spray alone and combined with humic acid or/and chitosan on growth, nutrient elements content and yield of dry bean (Phaseolus vulgaris L.) plants sown at different dates. Sci Hort 184: 101-105. https://doi. org/10.1016/j.scienta.2014.11.010

Iriti M, Picchi V, Rossonia M, Gomarasca S, Ludwig N, Gargano M, Faoro F (2009) Chitosan antitranspirant activity is due to abscisic acid-dependent stomatal closure. Environ Exp Bot 66:493-500. https://doi.org/10.1016/j.envexpbot.2009.01.004

Jayakumar R, Selvamurugan N, Nair SV, Tokura S, Tamura H (2008) Preparative methods of phosphorylated chitin and chitosanan overview. Int J Biol Macromol 43: 221-225. https://doi. org/10.1016/j.ijbiomac.2008.07.004

Kalaji MH, Guo P (2008) Chlorophyll fluorescence: a useful tool in barley plant breeding programs. In: Sanchez A, Gutierrez SJ (eds) Photochemistry research progress. Nova Publishers, New York, pp 439-463

Karimi LN, Khanahmadi M, Moradi B (2012) Accumulation and phytotoxicity of lead in Cynara scolymus. Indian J Sci Technol 5:3634-3641

Katiyar D, Hemantaranjan A, Singh B (2015) Chitosan as a promising natural compound to enhance potential physiological responses in plant: a review. Indian J Plant Physi 20(1):1-9. https://doi. org/10.1007/s40502-015-0139-6
Khan WM, Prithiviraj B, Smiyh DL (2002) Effect of foliar application of chitin oligosaccharides on photosynthesis of maize and soybean. Photosynthetica 40(4):621-624. https://doi. org/10.1023/A:1024320606812

Khokon AR, Uraji M, Munemasa S, Okuma E, Nakamura Y, Mori IC, Murata Y (2010) Chitosan induced stomatal closure accompanied by peroxidase-mediated reactive oxygen species production in Arabidopsis. Biosci Biotechnol Biochem 74(11):23132315. https://doi.org/10.1271/bbb.100340

Laranjeira MCM, Fávere VT (2009) Quitosana: biopolímero funcional com potencial industrial biomédico. Quim Nova 32:672678. https://doi.org/10.1590/S0100-40422009000300011

Lee SH, Chung GC (2005) Sensitivity of root system to low temperature appers to be associated with the hydraulic properties trough aquaporin activity. Sci Hortic 105:1-11. https://doi. org/10.1016/j.scienta.2005.01.013

Lee SH, Choi S, Suh JS, Doo IS, Oh KY (1999) Oligogalacturonic acid and chitosan reduced stomatal aperture by inducing the evolution of reactive oxygen species from guard cell of tomato and Commelina communis. Plant Physiol 121(1):147-152. https ://doi.org/10.1104/pp.121.1.147

Li F, Ding C (2014) Optimization of ultrasonic synthesis of $N$-succinyl-chitosan and adsorption of $\mathrm{Zn}^{2+}$ from aqueous solutions. Desalin Water Treat 52(40-42):7856-7865. https://doi. org/10.1080/19443994.2013.833867

Li Z, Zhang Y, Zhang X, Merewitz E, Peng Y, Ma X, Huang L, Yan Y (2017) Metabolic pathways regulated by chitosan contributing to drought resistance in White Clover. J Proteome Res 16:3039-3052. https://doi.org/10.1021/acs.jproteome.7b00334

Limpanavech P, Chaiyasuta S, Vongpromek R, Pichyangkura R, Khunwasi C, Chadchawan S, Lotrakul P, Bunjongrat R, Chaidee A, Bangyeekhun T (2008) Chitosan effects on floral production, gene expression, and anatomical changes in the Dendrobium orchid. Sci Hortic 116: 65-72. https://doi.org/10.1016/j.scien ta.2007.10.034

Liu XF, Guan YL, Yang DZ, Li Z, Yao KD (2001) Antibacterial action of chitosan and carboxymethylated chitosan. J Appl Polym Sci 79:1324-1335

Lizarraga-Pauli EG, Torres-Pacheco I, Moreno-Martinez E, Miranda-Castro SP (2011) Chitosan application in maize (Zea mays) to counteract the effects of abiotic stress at seedling level. Afr J Biotechnol 10(34):6439-6446

Lopes MS, Araus JL, Van Heerden PDR, Foyer CH (2011) Enhancing drought tolerance in $\mathrm{C} 4$ crops. J Exp Bot 62:3135-3153. https://doi.org/10.1093/jxb/err105

Malerba M, Cerana R (2016) Chitosan effects on plant systems. Int J Mol Sci 17(7):996. https://doi.org/10.3390/ijms17070996

Martins M, Carvalho M, Carvalho DT, Barbosa S, Doriguetto AC, Magalhaes PC, Ribeiro C (2018) Physicochemical characterization of chitosan and its effects on early growth, cell cycle and root anatomy of transgenic and non-transgenic maize hybrids. Aust J Crop Sci 12:56. https://doi.org/10.21475/ajcs.18.12.01. pne649

Mondal MMA, Malek MA, Puteh AB, Ismail MR, Ashrafuzzaman M, Naher L (2012) Effect of foliar application of chitosan on growth and yield in okra. Aust J Crop Sci 6:918-921

Mondal MMA, Puteh AB, Dafader NC, Rafii MY, Malek MA (2013) Foliar application of chitosan improves growth and yield in maize. J Food Agric Environ 11:520-523

O' Neill PM, Shanahan JF, Schepers JS (2006) Use of chlorophyll fluorescence assessments to differentiate corn hybrid response to variable water conditions. Crop Sci 46:681-687. https://doi. org/10.2135/cropsci2005.06-0170

Patrick DJ (2015) Plant biostimulants: definition, concept, main categories and regulation. Sci Hortic 196:3-14. https://doi.org/10.1016/j. scienta.2015.09.021 
Peltier G, Cournac L (2002) Chlororespiration. Annu Rev Plant Biol 53:523-550. https://doi.org/10.1146/annurev.arplant.53.10030 1.135242

Perdomo JA, Capó-Bauçà S, Carmo-Silva E, Galmés J (2017) Rubisco and rubisco activase play an important role in the biochemical limitations of photosynthesis in rice, wheat, and maize under high temperature and water deficit. Front Plant Sci 8:490. https://doi. org/10.3389/fpls.2017.00490

Pichyangkura R, Chadchawan S (2015) Biostimulant activity of chitosan in horticulture. Sci Hortic 196:49-65. https://doi. org/10.1016/j.scienta.2015.09.031

Pirbalouti AG, Malekpoor F, Salimi A, Golparvar A (2017) Exogenous application of chitosan on biochemical and physiological characteristics, phenolic content and antioxidant activity of two species of basil (Ocimum ciliatum and Ocimum basilicum) under reduced irrigation. Sci Hortic 217:114-122. https://doi.org/10.1016/j.scien ta.2017.01.031

Pongprayoon W, Roytrakul S, Pichayangkura R, Chadchawan S (2013) The role of hydrogen peroxide in chitosan-induced resistance to osmotic stress in rice (Oryza sativa L.). Plant Growth Regul 70:159-173. https://doi.org/10.1007/s10725-013-9789-4

Pospisilova J (2003) Participation of phytohormones in the stomatal regulation of gas exchange during water stress. Biol Plant 46:491506. https://doi.org/10.1023/A:1024894923865

Povero G, Loreti E, Pucciariello C, Santaniello A, Di-Tommaso D, Di-Tommaso G, Kapetis D, Zolezzi F, Piaggesi A, Perata A (2011) Transcript profiling of chitosan-treated Arabidopsis seedlings. J Plant Res 124:619-629. https://doi.org/10.1007/s1026 5-010-0399-1

Ramírez M, Rodriguez AT, Alfonso L, Peniche C (2010) Chitin and its derivatives as biopolymers with potential agricultural applications. Biotechnol Appl 27:270-276

Rinderle U, Lichtenthaler KK (eds) (1988) Applications of chlorophyll fluorescence. Kluwer Academic Publishers, Dordrecht

Saglam A, Kadioglu A, Demiralay M, Terzi R (2014) Leaf rolling reduces photosynthetic loss in maize under severe drought. Acta Bot Croat 73(2):315-332. https://doi.org/10.2478/botcr o-2014-0012

Sharathchandra RG, Niranjan S, Shetty NP, Amruthesh KN, Shekar $\mathrm{H}$ (2004) A chitosan formulation Elexa induces downy mildew disease resistance and growth promotion in pearl millet. Crop Protect 23:881-888. https://doi.org/10.1016/j.cropro.2003.12.008

Sharp RG (2013) A review of the applications of chitin and its derivatives in agriculture to modify plant-microbial interactions and improve crop yields. Agronomy 3:757-793. https://doi. org/10.3390/agronomy3040757

Signini S, Campana-Filho SP (2001) Characteristics and properties of purified chitosan in the neutral, acetate and hydrochloride forms. Polímeros 11:58-64. https://doi.org/10.1590/S0104-1428200100 0200007

Souza TC, Castro EM, Magalhaes PC, Lino LO, Alves ET, Albuquerque PEP (2013a) Morphophysiology, morphoanatomy, and grain yield under field conditions for two maize hybrids with contrasting response to drought stress. Acta Physiol Plant 35:3201-3321. https://doi.org/10.1007/s11738-013-1355-1

Souza TC, Castro EM, Magalhães PC, Castro EM, Albuquerque PEP, Marabesi MA (2013b) The influence of ABA on water relation, photosynthesis parameters, and chlorophyll fluorescence under drought conditions in two maize hybrids with contrasting drought resistance. Acta Physiol Plant 35:515-527. https://doi. org/10.1007/s11738-012-1093-9

Souza TC, Magalhães PC, Castro EM, Carneiro NP, Padilha FA, Gomes Júnior CC (2014) ABA application to maize hybrids contrasting for drought tolerance: changes in water parameters and in antioxidant enzyme activity. Plant Growth Regul 73:205-2017. https://doi.org/10.1007/s10725-013-9881-9

van Kooten O, Snel J (1990) The use of chlorophyll fluorescence nomenclature in plant stress physiology. Photosynth Res 25:147150. https://doi.org/10.1007/BF00033156

Wang X, Vigjevic M, Liu F, Jacobsen S, Jiang D, Wollenweber B (2015) Drought priming at vegetative growth stages improves tolerance to drought and heat stresses during grain fi lling in spring wheat (Triticum aestivum L. cv. Vinjett). Plant Growth Regul 75:677-687. https://doi.org/10.1007/s10725-014-9969-x

Yan H, Wu L, Filardo F, Yang X, Zhao X (2017) Chemical and hydraulic signals regulate stomatal behavior and photosynthetic activity in maize during progressive drought. Acta Physiol Plant 39:125. https://doi.org/10.1007/s11738-017-2418-5

Yang F, Hu J, Li J, Wu X, Qian Y (2009) Chitosan enhances leaf membrane stability and antioxidant enzyme activities in apple seedlings under drought stress. Plant Growth Regul 58:131-136. https://doi.org/10.1007/s10725-009-9361-4

Yao Y, Liu X, Li Z, Ma X, Rennenberg H, Wang X, Li H (2013) Drought-induced $\mathrm{H}_{2} \mathrm{O}_{2}$ accumulation in subsidiary cells is involved in regulatory signaling of stomatal closure in maize leaves. Planta 238:217-227. https://doi.org/10.1007/s0042 5-013-1886-0

Zeng D, Luo X (2012) Physiological effects of chitosan coating on wheat growth and activities of protective enzyme with drought tolerance. Open J Soil Sci 2:282-288. https://doi.org/10.4236/ ojss.2012.23034

Zeng K, Deng Y, Ming J, Deng L (2010) Induction of disease resistance and ROS metabolism in navel oranges by chitosan. Sci Hortic 126:223-228. https://doi.org/10.1016/j.scienta.2010.07.017

Zhang H, Zhao X, Yang J, Yin H, Wang W, Lu H, Du Y (2011) Nitric oxide production and its functional link with OIPK in tobacco defense response elicited by chitooligosaccharide. Plant Cell Rep 30:1153-1162. https://doi.org/10.1007/s00299-011-1024-z

Zhang X, Li K, Liu S, Xing R, Yu H, Chen X, Li P (2016) Size effects of chitooligomers on the growth and photosynthetic characteristics of wheat seedlings. Carbohydr Polym 138:27-33. https://doi. org/10.1016/j.carbpol.2015.11.050

Zou P, Li K, Liu S, Xing R, Qin Y, Yua H, Zhou M, Li P (2015) Effect of chitooligosaccharides with different degrees of acetylationon wheat seedlings under salt stressing. Carbohydr Polym 126:62-69. https://doi.org/10.3390/molecules22111903 